\title{
Impact Assessment and Prioritization of Critical Delay Factors for a Road Project
}

\author{
Harish L Reddy ${ }^{*}$, M S Nagakumar, Swathi H \\ Department of Civil Engineering, R. V. College of Engineering, Bengaluru, India
}

Received September 29, 2020; Revised November 21, 2020; Accepted December 6, 2020

\section{Cite This Paper in the following Citation Styles}

(a): [1] Harish L Reddy, M S Nagakumar, Swathi H, "Impact Assessment and Prioritization of Critical Delay Factors for a Road Project," Civil Engineering and Architecture, Vol. 8, No. 6, pp. 1325 - 1334, 2020. DOI: 10.13189/cea.2020.080616.

(b): Harish L Reddy, M S Nagakumar, Swathi H (2020). Impact Assessment and Prioritization of Critical Delay Factors for a Road Project. Civil Engineering and Architecture, 8(6), 1325 - 1334. DOI: 10.13189/cea.2020.080616.

Copyright $\mathrm{C} 2020$ by authors, all rights reserved. Authors agree that this article remains permanently open access under the terms of the Creative Commons Attribution License 4.0 International License

\begin{abstract}
Indian road sector has witnessed significant changes from the year 2014. The new government administrators and the ministry of road transport and highways have brought in various policy reforms, foreign investments and special drive to push the road construction activities. The ministry had initially planned to build roads at a pace of $40 \mathrm{~km} /$ day but only achieved construction of 32 $\mathrm{km} /$ day. In addition, a number of projects are pending which have been collectively taken up under the newly launched Bhartmala pariyojana scheme. There exist some constraints/factors within various stages of planning and execution, which is responsible for delays. The main focus of this study was to carry out an assessment of the impact of delay factors and prioritize them for a road project. A questionnaire survey followed by informal interviews was carried out to identify and assess the impact of various delays occurring in road projects in India. Data were collected amongst senior project stakeholders from government departments, consultants, contractors, and academicians. The response data were statistically analyzed and the results were used on a sample road project. A 4D virtual model of the entire stretch was made. A list of delays apt for the project was identified and their impacts on planned schedule and cost were found. The data were run on a monte carlo simulation platform for various outcomes on project planned time and cost. The simulation results revealed critical delay factors responsible for major delays in the road project. The critical delay factors are to be properly targeted, handled, and managed to ensure success in project completion. The findings of this study will greatly benefit stakeholders in road construction to identify and control the critical delay factors.
\end{abstract}

Keywords Road project, Critical Delay, 4D Modelling, Monte Carlo Simulation

\section{Introduction}

India is a nation presently possesses the second largest road network in the world. The extensive road network provides numerous opportunities for national and international investors alike. The future of the Indian road sector looks magnanimous and will undoubtedly be engulfed with challenges and complexities across various stages. Also, the road sector is often fraught with time delays and cost overruns. A review of several pieces of literature from national, international journals, government circulars, and news articles, reveals that many factors are responsible for these time delays and cost overruns. An article in a leading newspaper dated $10^{\text {th }}$ Nov 2019, reads as follows: "Total original cost of implementation of the 1,623 projects was Rs 19,33,390.22 crore and their anticipated completion cost is likely to be Rs 23,21,502.84 crore, which reflects overall cost overruns of Rs 3,88,112.62 crore (20.07 percent of original cost)"[1].

A brief note of a few road projects taken at random shows the nature of delays occurring in India. Example 1: "Rehabilitation and Upgradation of Teleibani-Sambalpur section of NH-06 from Km. 493.00 to Km. 521.30 \& Km. 545.176 to $\mathrm{Km}$. 567.40 " in the state of Odisha under NHDP-IV-B was given under EPC mode. The project was 
started on 25 May 2017 and was scheduled to complete by 20 November 2019. The present anticipated completion date is 27 March 2021. The reasons cited for delay are 1) Poor financial management by EPC contractor, 2) land acquisition problems, 3) forest clearances needed, 4) utility shifting delays, 5) railway clearance needed 6) removal of encroachments 7) tree cutting involved and 8) removal of religious/ government structures [2].

Example 2: "Rehabilitation, Strengthening and Four laning of Banihal to Srinagar Km 187.00 to Km. 286 (except tunnel portion i.e., Km 189.35 to Km. 204.70)" under NHDP - Phase II/BOT/J\&K was scheduled to be completed by 25 June 2014. The project status as of 26 Dec 2019 stands at $90 \%$. The reasons for the delay being 1) Delay in disbursement of land compensation and removal of obstructions from the right of way by the State Government, 2) Inadequate mobilization of funds and resources by the concessionaire, 3) Floods in the valley in Sept 2014 [2].

Example 3: "Six laning of Vijayawada - Gundugolanu section of NH-16 (Old NH-5) including Hanuman junction bypass and Vijayawada Bypass" under DBFOT (Toll) basis was commenced on 21 March 2012 and was expected to complete by 2016. The contract got terminated due to the non-achievement of financial closure by the concessionaire. The project was subsequently split into 4 packages out of which 2 are presently taken up under EPC mode and 2 are proposed to be taken up under HAM [2].

There are such ample numbers of project case examples showcasing the successful repetition of delays and failures across road projects. These delays will undoubtedly hamper economic development at the regional and national levels. The importance and criticality of these delay factors on road projects in India are not identified and assessed in great detail. The objective of this paper is to 1) Ascertain the primary reasons for delays of road projects in India, 2) To arrive at an estimate of the probability of occurrence and likely impact of delay factors, and 3) To simulate the effect of delays and determine the critical delay factors along with their impacts.

This study will eventually help practitioners to strategize measures in controlling these factors and eventually improve success in the delivery of road projects.

\section{Literature Review}

The Delay management process involves the identification of hindrances or delay factors, their assessment, and continuous management during the project. The principal outputs will be to determine the probabilistic estimates of project cost and project schedule and assessment of the potential impact of delay factors [3]. The complex situations and difficulty in factor identification often restrict the use of an effective static system for evaluation. This makes the engineers rely on expert estimation utilizing their professional knowledge, experience, and intuition [4].

The delay management tool will provide the concerned stakeholders with a list of the most sensitive or critical factors with emphasis on their ranges of probability and likely contingencies they will need [5]. Many computer modeling techniques have been developed to assist in the decision making process under uncertainty. Uncertain environments, continuous changes in project scope during execution, increase in the size of the project, etc. have made it difficult for practical application of these models [6].

Each method of analysis comes with its advantages and disadvantages. While some methods such as brainstorming, checklists, risk registers are simple and do not stress detailed project information, other methods such as simulations, fuzzy logics rely on detailed project information and the use of specialized software for risk assessment. No one solution fits all. Also, with the latest advancement in technology and soft computing, the risk assessment methods are evolving giving more accurate results while at the same becoming more complex.

Among these, the Monte Carlo simulation method performs a large number of iterations to arrive at numerous possible outcome scenarios for given data. Each time a random input value is selected from the probability distribution and the model is run to determine the output [7]. The Monte Carlo simulation method provides an opportunity to make the delays calculable [8]. Monte Carlo analysis carries out statistical iterations sufficient enough to cover the possible range of outputs. The output accuracy depends on the correct identification and accuracy of input parameters [9]. These cost and schedule impacts of project delays can be validated by conducting case study investigations [10].

Another method of analysis, the Building information modeling (BIM) or in this case road information modeling (RIM) has evolved from simple 3D modeling of buildings to $5 \mathrm{D}$ modeling of infrastructure projects. The managerial strategies and issues encountered are rather different for infrastructure projects as compared to traditional building projects [11]. BIM integrates all the project life cycle activities such as design, construction, and operation into one single model along with a communication platform [12]. But, the use of BIM tools is limited due to the lack of qualified experts and the upfront technology cost. The research into the application of BIM in handling delays is still widely open. And there is a need to explore a detailed methodology for using BIM for delay management [13, 14]

It is observed by the authors that the knowledge of delay and risk management are largely learned on the job and seldom through formal education. It is observed that most of the syllabus covering civil engineering and/or 
construction management does not cover risk management course [15]. Nevertheless, engineers and practitioners should be made aware of the potential benefits of delay as well as risk management in their projects. Delay and risk management should not be limited to their qualitative aspects wherein experience, subjective judgments, and intuition play a major role in practical applications [16, 17].

In addition to formalizing the delay management process, there is a need to prepare a large pool of delay information from past projects. This will support the formulation of probability distributions of delay events for the future. Also, it will reduce the necessity of subjective judgment in the decision making process [18].

\section{Methodology}

The methodology followed for this research study are 1) literature review and questionnaire surveys to identify major delay factors impacting road projects in India; 2) informal interviews and expert elicitation to validate delay factors and assess probability and impact of these factors on road projects; 3) 4D modeling of selected road project as a case study and probabilistic simulation of delay factors to deduce most critical delay factors.

Commercially available software's such as AutoCAD CIVIL 3D, Navisworks, Infraworks, and @RISK simulation software is used for analysis.

\subsection{Questionnaire Survey for Identification of Delay Factors}

To get firsthand information on various causes of delays in construction projects, a detailed literature review was carried out as summarized in the earlier section. The prepared list of delay factors is shown in Table $\mathbf{I}$. Non-availability of an information database on road projects prompted for conducting a questionnaire survey among experts in road projects. This was done to validate the list prepared from the literature review. Due to the limited availability of experts in the field, snowball sampling was done to select known experts in the field through primary and secondary contacts. These experts were identified from the client, consultant, and contractor's team, working on road projects. In addition, few respondents were also included from academia who were actively involved in the research.

The questionnaire form was divided into three sections. The first section collected information relating to the respondent. The second section assessed information related to the awareness of delay management in road projects. The third section expounded response from experts on the probability and impact of various delay factors occurring in road projects. The questionnaire was personally given to the experts and responses were taken in the presence of surveyors. This was done to avoid any mistakes as well as to answer any queries from the experts. In some cases, experts were busy with their work schedule, and responses were taken at their convenience. Out of 40 experts contacted for elicitation of responses, 21 responses were found to be complete and correct. The response rate was $52.5 \%$. Though the number of respondents was limited, the reliability is expected to be high as they were qualified professionals in their field. The 21 respondents were having an average experience of more than 15 years in road projects at the time of the survey. The 21 completed survey responses were used for further analysis.

Table 1. Classified List of Delay Factors in Road Projects

\begin{tabular}{cl}
\hline Category & \multicolumn{1}{c}{ Factors* } \\
\hline Client related & $\begin{array}{l}\text { Changes in project team, Poor crisis management, Distrust with other parties, Delay in bill approvals, Unwarranted } \\
\text { interferences, Changes in policies, Imposing penalties and levies, Misleading items, Design errors, Slow dispute } \\
\text { resolutions }\end{array}$ \\
\hline Contractor related & $\begin{array}{l}\text { Delay in response to changes, Joint venture/ownership problems, Too many work order/book items, Sub-contractor } \\
\text { related problems, Poor planning and control, Blacklisting, Poor communication, Lack of experience }\end{array}$ \\
\hline Site-related & $\begin{array}{l}\text { Site interferences/obstructions, Competing nearby projects, Influence of political bodies/ NGOs, Influence of other } \\
\text { government bodies, Existing features/elements, Presence of utilities, Buildings of importance, Existing traffic, } \\
\text { Agriculture/industrial activity, Varying site conditions, Accessibility problems, Unexpected economic development, } \\
\text { Safety and security issues, Storage and handling problems, Secondary pollutions, Health disorders }\end{array}$ \\
\hline Finance related & $\begin{array}{l}\text { Poor estimation and forecasts, Changes in fuel prices, Changes in resource prices, Changes in taxes/fees, } \\
\text { Monopoly/domination from selected parties, Lender related, Changes in lending policies, Withdrawal/limitation of } \\
\text { funds, Shortage of funds, Tedious accounting process/bureaucratic systems, Multiple approvals needed, } \\
\text { Transparency/Standard Operating Procedure (SOP) missing, Too many documents required, long approval process }\end{array}$ \\
\hline Manpower related & Local influence, Cultural challenges, Strikes, Lack of training and discipline, Accidents \\
\hline Equipment related & Disputes on work sharing, Loss in productivity, Failures/ breakdowns, Special requirements \\
\hline Material related & $\begin{array}{l}\text { Thefts, Monopoly by vendors, Rigid clauses on use of materials, Changes to specifications, Source depletion and/or } \\
\text { relocation, Defective/unsound materials, Poor site investigations, Non-availability of materials. }\end{array}$ \\
\hline Quality related & $\begin{array}{l}\text { Continued negligence, no quality system in place, poor supervision, errors and reworks, lack of automation, outdated } \\
\text { standards }\end{array}$ \\
\hline *Compiled by authors from [20], [21], [22], [23], [24], [25], [26]
\end{tabular}




\subsection{Risk Estimation}

In the questionnaire survey, the respondents were asked to assign a probability level for each delay factor. In addition, an assessment of the impact on time and cost aspect was made for each factor. The respondents were asked to rate the factors on a scale of $0-100 \%$. The scale was kept uniform for probability and impact assessment. As the respondents were from different stakeholder groups, a reliability index in the form of Cronbach's alpha was adopted to test the reliability of the data. A value above 0.7 would indicate acceptable data, and if it crosses 0.8 then the collected data is assumed good for analysis. Risks were estimated as the product of the probability of occurrence and impact on time or cost. Risks were estimated for time and cost separately for each factor. Some delay factors which had a negligible impact or low probability of occurrence were not included for final analysis. The top ten factors with a higher probability of occurrence and/or with higher impacts were then found.

\subsection{Building a 4-D Model of the Road Project}

To identify delay factors, a project case was taken up for study. The project is a part of a state highway network in the state of Karnataka, in India. The project length is about $12.5 \mathrm{~km}$ long. The project design and construction were completed by a local consulting firm. The project details were collected from the local consulting firm.

The project model was initially developed using AutoCAD Civil 3D software. The project was virtually designed and modeled as per relevant IRC standards followed in India. Once the model was done, the 3D elements were extracted from the software as 3D objects. These 3D objects were then imported into the Autodesk Navisworks platform for incorporating time aspect i.e. schedule of the project. Further, simulations were run to visualize the complete construction of the road project as per schedule. The model was then analyzed to identify probable delay factors in the project.

\subsection{Risk Simulation}

To estimate the impact of any single delay factor or a combination of delay factors on the project, simulations were necessary. @RISK software provided by palisade solutions was used for this purpose. @RISK is an add-in to Microsoft excel and analyzes all possible outcomes of a situation based on the Monte Carlo technique. The software incorporates the project schedule with delay factors and runs simulations using the probability and impact factors to compute the overall impact on the project. The software easily integrates with the Microsoft Project schedule. The project schedule included activities, their durations, and start and finish dates along with relationships and cost values. A simplified version of the project schedule used for analysis is shown in Table II.

In @ RISK software, a Risk Register is first prepared which calculates the time and cost impacts of individual risk factors and links them to the project schedule. A number of iterations are carried out by selecting a risk probability and impact factors at random. The simulation stops when the mean and standard deviation of all the simulations converge. The formulae used in the Risk register are as follows. Column An - Risk Number; Column Bn - Risk Categories; Column Cn - Risk Factors; Column Dn - Probability of Occurrence; Column En = Probability of Non Occurrence $=1$-Column Dn; Column $\mathrm{Fn}=$ Simulated Occurrence = RiskDiscrete( $\{1,0\}$, Dn:En ,RiskStatic (0)); Column Gn = IF(Fn>0,"Yes","No"); Column Hn,Nn = Blank; Column [In, Jn and Kn] : [Minimum, Most Likely and Maximum] impact of Risk factors on project time; Column On, Pn and Qn: Minimum, Most Likely and Maximum impact of Risk factors on project cost; Column $\mathrm{Ln}=$ Simulated Schedule Impact $=$ RiskPert $(\mathrm{In}, \mathrm{Jn}, \mathrm{Kn}) * \mathrm{Dn} * \mathrm{Fn}$; Column $\mathrm{Mn}=$ Simulated days added to plan =RiskMakeInput ( $n^{*} F n$, RiskName (Cn\&" Schedule Impact")); Column $\mathrm{Rn}=$ Simulated Cost impact $=$ RiskTriang $(\mathrm{On}, \mathrm{Pn}, \mathrm{Qn}$, RiskName(Cn\&" /"\&\$R\$n)); Column $\mathrm{Sn}=$ Simulated Cost added to plan $=$ RiskMakeInput $\left(\mathrm{Rn}^{*} \mathrm{Fn}\right.$, RiskName $\left(\right.$ Cn\&" Cost Impact")). Here, ' $n$ ' is the ${ }^{\text {th }}$ Risk factor.

Table 2. Road project schedule

\begin{tabular}{ccccc}
\hline Project Activities & Planned Duration & Planned Start & Planned Finish & Estimated Cost Rs in Lakhs \\
\hline Earthwork & 14 days & $01-02-2018$ & $14-02-2018$ & $₹ 405.00$ \\
GSB & 34 days & $03-02-2018$ & $09-03-2018$ & $₹ 255.00$ \\
DLC & 37 days & $07-02-2018$ & $16-03-2018$ & $₹ 573.75$ \\
PQC( LHS ) & 57 days & $17-02-2018$ & $15-04-2018$ & $₹ 956.25$ \\
PQC ( RHS $)$ & 53 days & $05-03-2018$ & $30-04-2018$ & $₹ 956.25$ \\
Culverts & 26 days & $01-02-2018$ & $26-02-2018$ & $₹ 11.10$ \\
Bridges & 53 days & $01-02-2018$ & $25-03-2018$ & $₹ 76.80$ \\
Guard wall & 32 days & $26-04-2018$ & $27-05-2018$ & $₹ 4.20$ \\
\hline
\end{tabular}


The simulation is run in the @ RISK and Microsoft project at the same time. 1000 iterations per trial were done for different combinations of delay factors. @RISK software assigns the probability and impact of delay factor to each activity and calculates the change in planned duration and cost. This is then sent to Microsoft Project for scheduling. Microsoft project then determines the changes in overall project duration and cost which is then sent back to@ RISK software. In this manner, @RISK assigns different values of probability and impact of each delay factor on activities and runs the simulation with Microsoft Project, and determines the changes in project duration. The effect of a single delay factor can also be found by assigning factors one by one and estimating its impact. This will indicate critical delay factors which may account for maximum impact on project cost and time. This process will help to prioritize and list critical delay factors for any road project.

\section{Findings}

\subsection{Delay Factors and Their Assessment}

Table 3. Reliability Statistics

\begin{tabular}{|l|l|l|}
\hline Cronbach's alpha & 0.772 & Time \\
\hline Cronbach's alpha & 0.528 & Cost \\
\hline
\end{tabular}

Table 4. Top ten delay factors based on their impacts

\begin{tabular}{ccc}
\hline \multirow{2}{*}{ Rank } & \multicolumn{2}{c}{ Top ten factors based on } \\
\cline { 2 - 3 } & Impact on cost & Impact on time \\
\hline 1 & $\begin{array}{c}\text { Poor planning and } \\
\text { control }\end{array}$ & Poor supervision of works \\
\hline 2 & Changes in fuel prices & Poor communication \\
\hline 3 & Continued negligence & No quality system in place \\
\hline 5 & Out of date/ obsolete & Site \\
standards & interferences/obstructions \\
\hline 6 & No quality system in & Poor crisis management \\
\hline 7 & Poor supervision & Poor planning and control \\
\hline 8 & Changes in resource & Distrust among stakeholders \\
\hline 9 & Poor communication & Late bill approvals \\
\hline 10 & Errors and reworks & Out of date/ obsolete \\
standards
\end{tabular}

21 responses from the questionnaire survey were first subjected to reliability analysis to test for internal consistency among respondents. Cronbach's alpha was used as a measure of internal consistency. Statistical analysis software package SPSS was used for analysis. The Cronbach's alpha value obtained was 0.772 for responses related to time and 0.528 for responses related to cost as shown in Table 3. The responses were considered reliable for time-related evaluation and hence, the time-related data was further analyzed. The responses related to cost information resulted in an alpha value below the threshold limit. This could be because of natural secrecy towards cost-related items and difference in opinion on how the cost is perceived by different stakeholders within a project. The factors were ranked based on their impacts on the time and cost of the project. The top ten factors as identified through the questionnaire survey are shown in Table 4.

\subsection{D Model of the Project}

3D solid elements of the road project were linked to the project schedule and simulations were run to visualize the construction process on the computer screen. 3D extraction and linking with schedule presented many challenges. 1) The entire project cannot be extracted as one solid 2) Pavement layers may be constructed in sequence and at different time intervals depending on the thickness. 3) $3 \mathrm{D}$ rendering of the project along with road inventory details puts a great requirement on the processing capabilities of the computer system 4) Some of the elements of the $3 \mathrm{D}$ model do not seamlessly integrate from Civil 3D to Navisworks as well project schedule from Microsoft Project or Primavera does not seamlessly link to $3 \mathrm{D}$ objects. 5) The road project generally runs to many kilometers and it is difficult to properly visualize the simulation process.

The challenges were thoroughly addressed to effect the $4 \mathrm{D}$ model creation. 1) The project was split into multiple sections before the extraction of 3D solids. The location of the split was decided based upon the planned schedule 2) A 16 GB RAM along with 2 GB graphics card is found suitable to handle data of this project. If the project length becomes higher, it is recommended to split the project into packages of $20-25 \mathrm{~km}$ long at suitable intersections/control points and handling the same as separate files. 3) Multiple viewpoints have to be established along the length of the project according to the time frame in the schedule such that the user can visualize construction according to the timeline. This is a time-consuming process and it was found inevitable at this point in time. 4) Any constraint / sensitive locations lying within the project road stretch have to be dealt with in isolation for seamless visualization.

The corridor models and $3 \mathrm{D}$ solid extracts are shown in Figure 1 to Figure 3. The effectiveness of the model in a virtual visualization of the road clearly depended on the type and amount of information input into the software. Faulty government records, limited road surveys, interdepartmental data, sensitive areas, changing underground soil conditions and hidden items reduce the accuracy of virtual models. If such areas can be identified beforehand, then special precautions can be taken to collect necessary data of such locations and building an isolated $4 \mathrm{D}$ model for the same. 


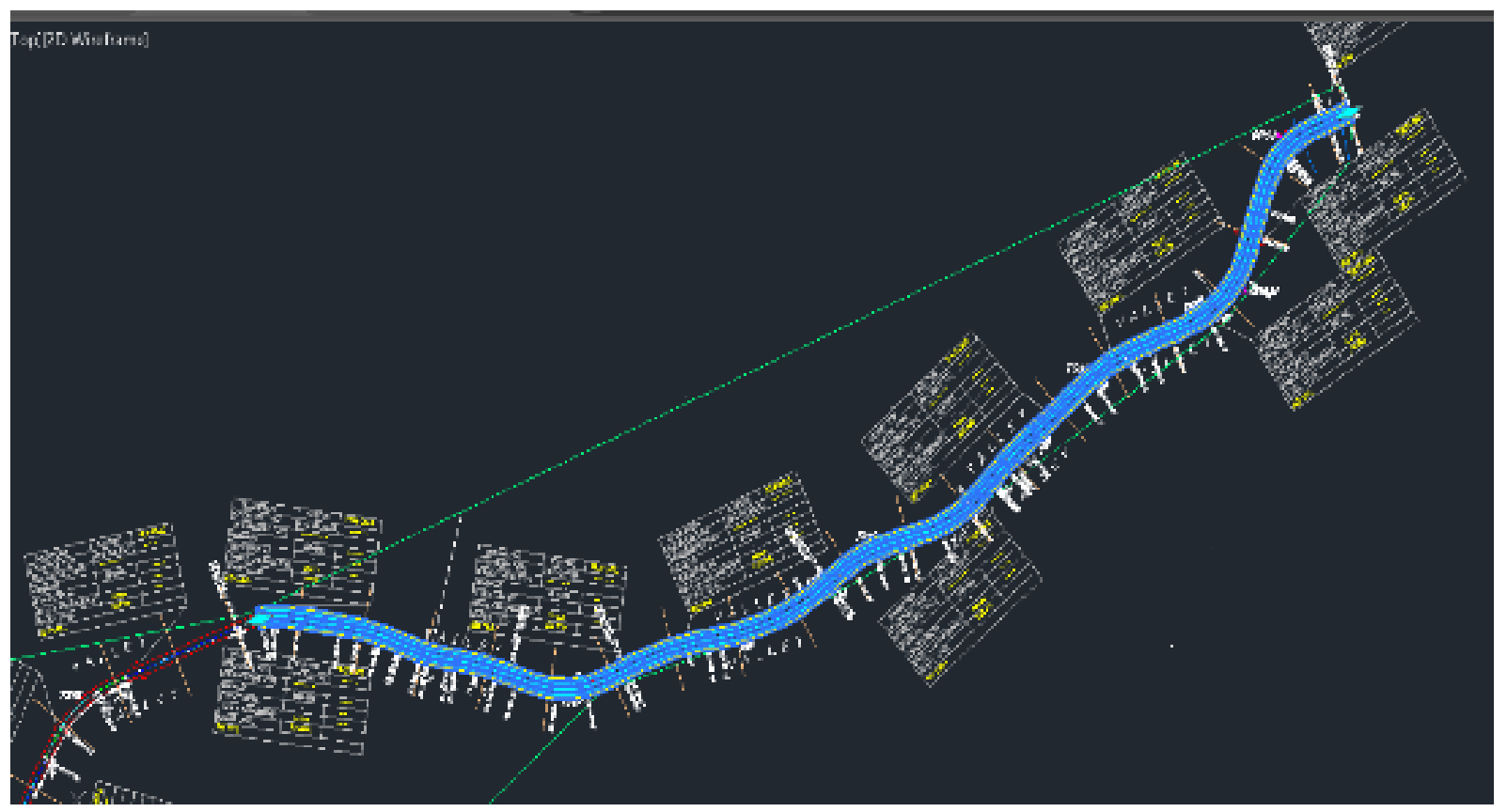

Figure 1. Corridor generation in Civil 3D

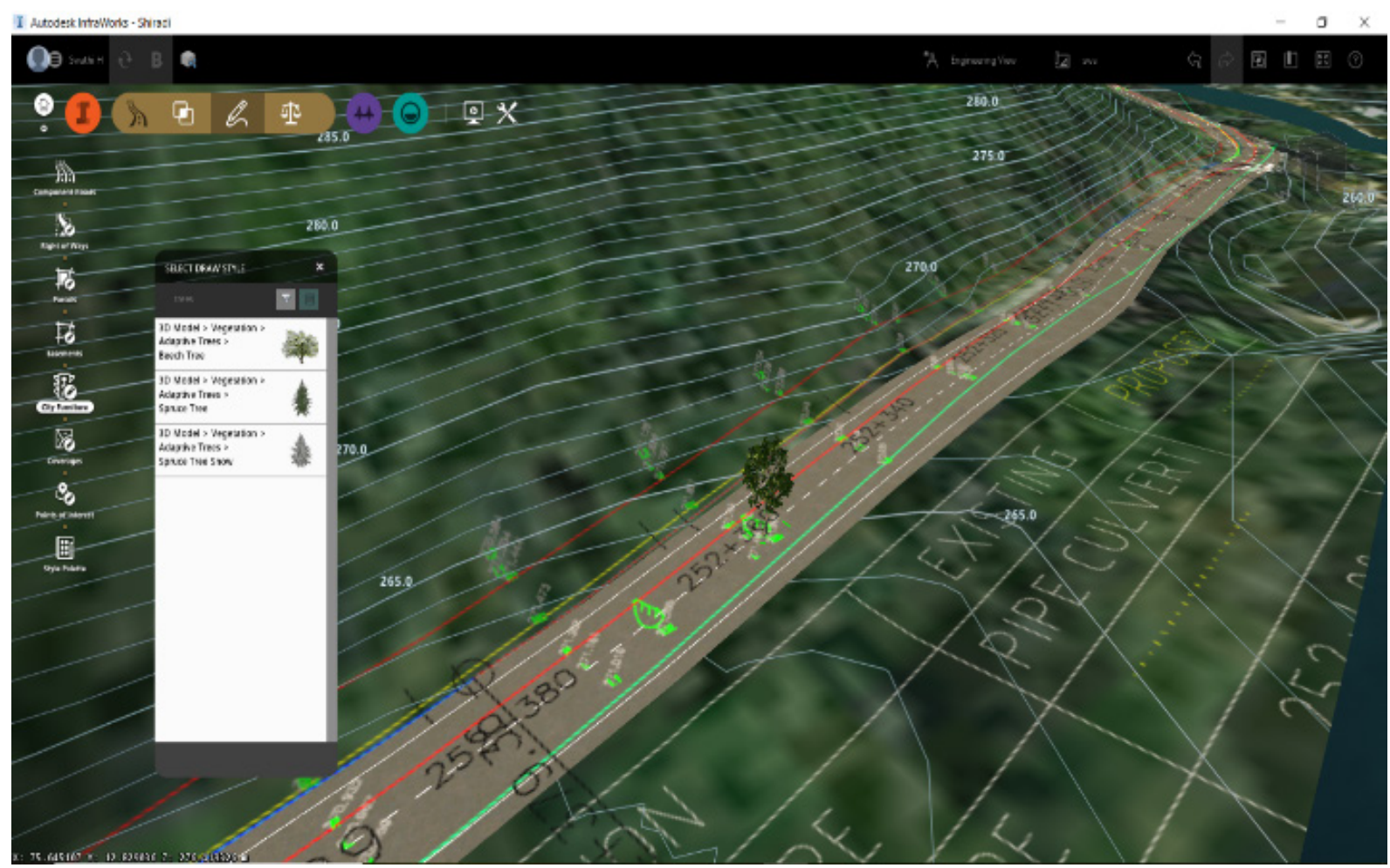

Figure 2. 3D Model generation using Civil 3D and Infraworks 


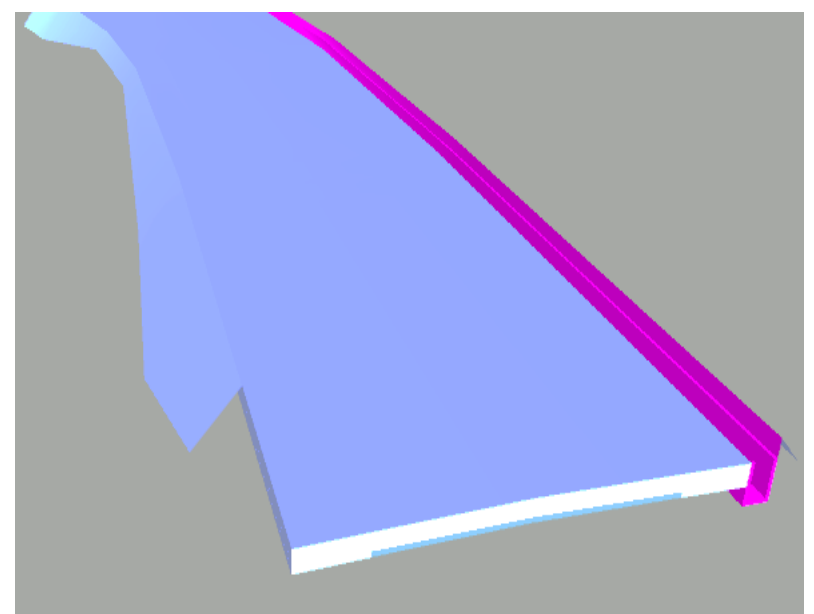

Figure 3. 3D solid extraction and import to Navisworks

\subsection{Impact of Delay on the Project}

The shortlisted factors along with their impacts were integrated with the project schedule (shown in Table 2) in the @RISK software platform. To assign factors to specific activities, a focus group was established with five experts from academia. The objective was to identify the relationship between a factor and a specific activity of the project. An assumption was made here that the impact of the delay factor (assessed during the survey) would

remain the same irrespective of the activity to which it is assigned. This assumption is reasonable because some factors such as 'poor supervision' will produce similar negative effects irrespective of the activity and the overall impact is measured in percentages. The magnitude of the impact will vary depending on the amount of time and cost assigned to each activity.

The project schedule is then simulated incorporating delays. The output will show changes in schedule due to the presence of delay factors. Several iterations were run within the probability distribution range of values for each delay factor corresponding to each activity. The results find that, if no delays were to occur, then the project would finish as per the planned date i.e., on 27 May 2018. But, with the presence of delay, this date would naturally get extended. If all the delay factors were to occur in the project, then simulation shows that the worst-case scenario for the project is to complete on 20 May 2019, nearly one year beyond schedule. In a similar manner, simulations were run with cost data. If no delay was to occur, then the project would be completed at a planned cost of Rs. 39.39 Crores. And in the worst-case scenario, where all delays were to occur, the project would be completed at a cost of Rs. 73.90 Crores. The Simulation charts for time and cost are shown in Figure 4 and Figure 5.

\section{Simulated Finish}

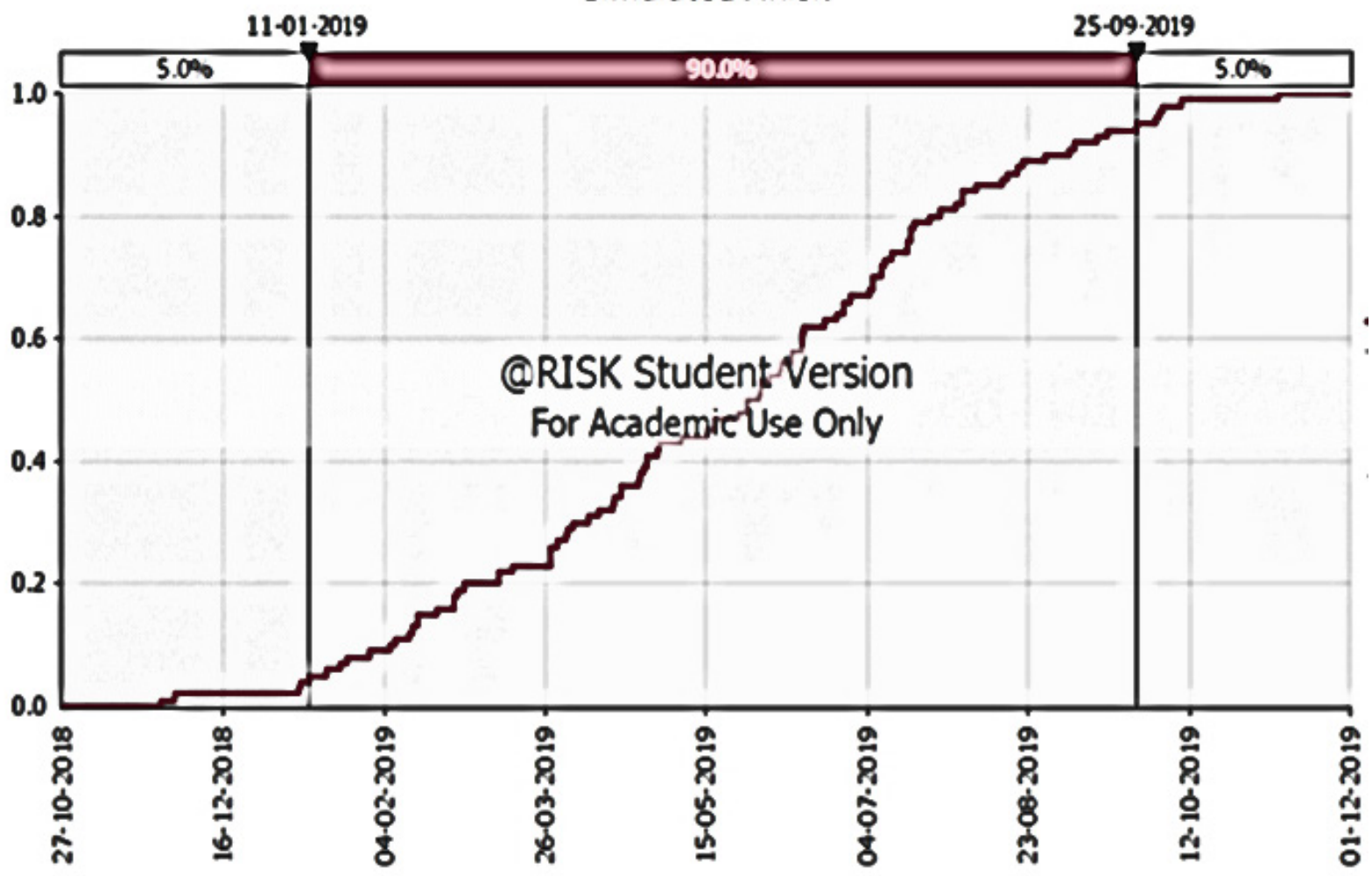

Figure 4. Simulation chart for impact on Time 


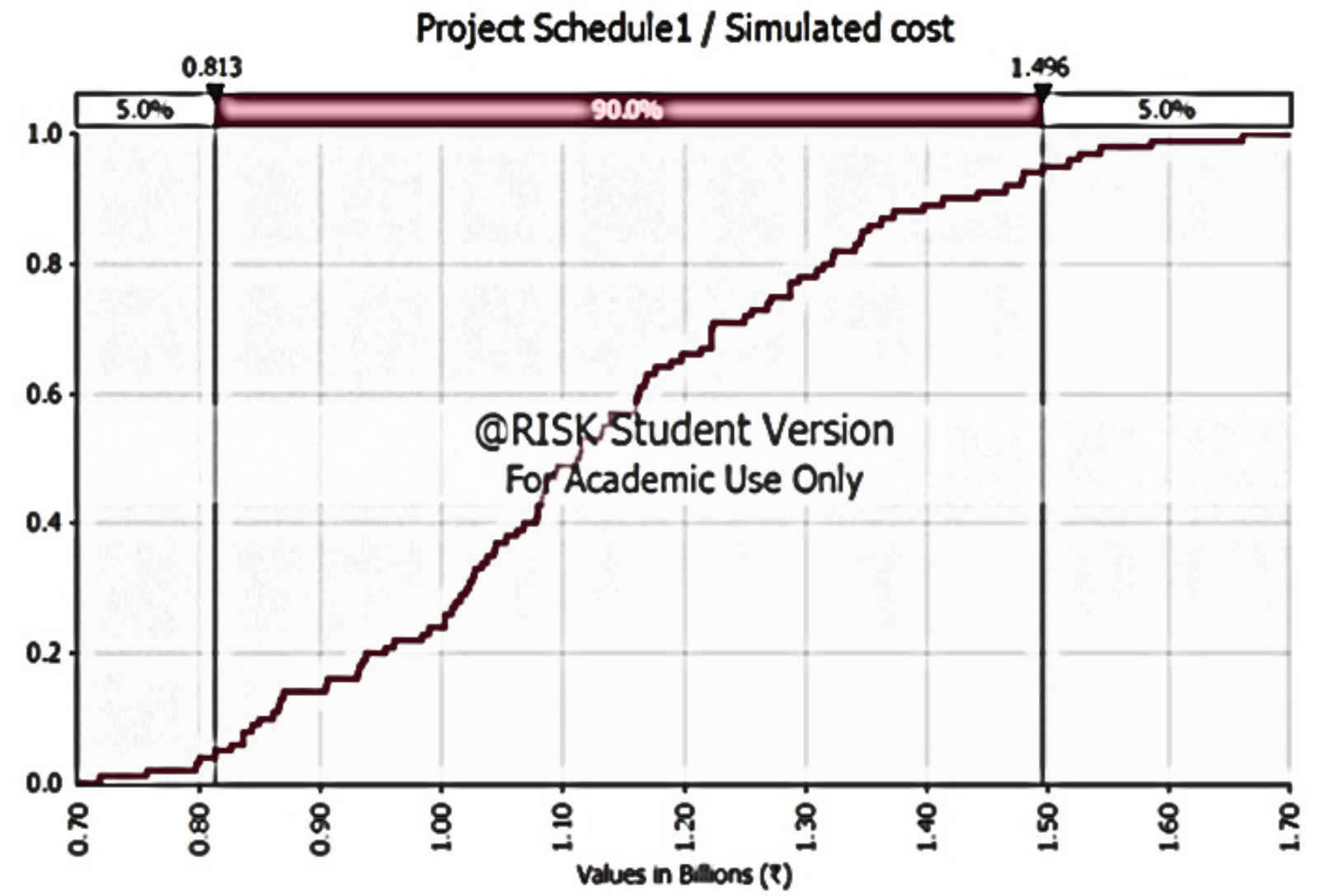

Figure 5. Simulation chart for impact on Cost

\subsection{Individual Impact Assessment and Prioritization of Delays}

It is important to understand the individual impact of each delay factor on the project along with their combined impacts. A higher probability of occurrence or higher impact value may not necessarily mean it is critical for the project. This is because, the number of repetitions of a single factor within a project and the activity to which it is related plays a major role. Hence, after assigning all the delay factors to their respective activities, the total impact of each factor was assessed. This was mainly done to prioritize the factors based on their overall impact and to highlight the importance of a mitigation measure for a particular delay factor.

Isolated impacts were assessed in two steps. In the first step, all factors were assigned and the overall impact was found. Let it be ' $\mathrm{X}$ '. In the second step, a candidate factor was assigned zero value and overall impact was found. Let it be ' $\mathrm{Y}$ '. The value of ' $\mathrm{Y}$ ' will always be less than ' $\mathrm{X}$ ' as there is the removal of the candidate factor causing the delay. The change in the overall impact between step 1 and step 2 i.e., $(\mathrm{X}-\mathrm{Y})$ is solely attributed to the absence of this candidate factor. In other words, if mitigation measures were to be in place to account for the candidate delay factor, there would be a reduction in project delay and cost overrun by $(\mathrm{X}-\mathrm{Y})$ amount.

The process was repeated for all delay factors to assess their individual impacts on the project. These factors then were arranged according to their individual impacts. The top ten factors were then selected as prominent factors contributing delay to the project. The top ten factors obtained from the analysis are shown in Table 5. This list differs slightly from the list shown in Table 4.

Table 5. Top ten delay factors based on Simulation Results

\begin{tabular}{|c|c|c|}
\hline Rank & Top Ten Factors & $\begin{array}{c}\text { Simulated Impact (time } \\
\text { delay + Cost overrun) }\end{array}$ \\
\hline 1 & Poor planning and control & $24.82 \%$ \\
\hline 2 & Poor quality management & $23.79 \%$ \\
\hline 3 & Poor supervision & $19.39 \%$ \\
\hline 4 & Accessibility problems & $18.85 \%$ \\
\hline 5 & Changes in fuel prices & $14.40 \%$ \\
\hline 6 & Non-availability of materials & $14.04 \%$ \\
\hline 7 & Lack of automation & $14.01 \%$ \\
\hline 8 & Site interferences/ & $12.91 \%$ \\
\hline 9 & obstructions & $11.11 \%$ \\
\hline 10 & Safety and security issues & $10.69 \%$ \\
\hline
\end{tabular}

\section{Conclusions}

This study started with a detailed literature review to 
bring about a classified list of factors responsible for delays in projects. These were found to be grouped under eight different categories i.e., Client related, Contractor related, Site related, Finance related, Manpower related, Equipment related, Material related, and Quality related. This list does not bring about the relative importance of any factors nor the impact of each factor on project time and cost. Hence, a questionnaire survey and informal interviews were carried out to assess the probability of occurrence of individual factors and their impacts on project time and cost. Nearly 71 factors were surveyed and the top ten factors were shortlisted. These factors were rated by experts based on their experience in road projects. There was consistent agreement among respondents regarding the impact of these factors on the time aspect of the project but differences existed on the cost aspect of the project.

To study the impacts of these factors on a road project, a sample road project was obtained. Details for a sample road project were sourced from a local consultant and a 4D model was generated based on available data. A construction schedule was prepared for the $4 \mathrm{D}$ model. The influence of these factors on the sample road project was analyzed through probabilistic simulation. The schedule was interposed with delay factors identified from the model and surveys. Several iterations were carried out to estimate the impact of an individual as well as the combined effect of delay factors on project time and cost.

A list of the top ten critical delay factors was finally arrived at. The final list indicated that the planning and control aspect of the road project plays a major role in limiting negative impacts on the project. This was followed by quality management, supervision of activities, site management, material management, technology management, safety management, and site investigations. Out of these changes in fuel prices is a global factor not in the control of project stakeholders.

The list of mitigation measures and their relative usefulness is not in the scope of this study. The methodology employed and the simulated results provide needed direction for project stakeholders to target their efforts in mitigating project delays and bringing project success.

\section{REFERENCES}

[1] "355 Infra Projects Show Cost Overruns of Rs 3.88 Lakh Crore", The Economic Times. https://economictimes.indiati mes.com/news/economy/infrastructure (accessed Nov. 1, 2019).

[2] Reddy, Harish (Assistant Professor, NICMAR), Project Director (NHAI). RTI Response Received Under RTI Act 2005, 2019-2020

[3] McGoey-Smith, A., Poschmann, A., Campbell, L, (2007)
"Quantitative Risk Assessment and Risk Management of a Large Transportation Project," Annual Conference and Exhibition of the Transportation Association of Canada: Transportation-An Economic Enabler (Les Transports: Un Levier Economique), 2007, pp. 01-18.

[4] Chaher, Z., Soomro, A. R, "Fuzzy Risk Analysis for Construction Projects," World Applied Sciences Journal, vol. 34 , no. 8, pp. 1010-1020, 2016. DOI: 10.5829/idosi.wasj.2016.34.8.70

[5] Mohammed S., Hashem M. Mehany, Angela Acree Guggemos , "Risk-Managed Lifecycle Costing for Asphalt Road Construction and Maintenance Projects under Performance-Based Contracts," ASCE-ASME Journal of Risk and Uncertainty in Engineering Systems, Part A: Civil Engineering, vol. 2, no. 4, pp. 01-10, 2016. https://doi.org/10.1061/AJRUA6.0000888

[6] Radionovs, A., Rebrov, O. U, Oleg, “Application of Fuzzy Logic for Risk Assessment," Information Technology and Management Science, Vol.17, pp. 50-54, 2014. DOI: 17. 10.1515/itms-2014-0007.

[7] Victor Platon, Andreea Constantinescu, "Monte Carlo Method in Risk Analysis for Investment Projects," Procedia Economics and Finance, Elsevier B.V, vol. 15, pp. 393 - 400, 2014. DOI: $10.1016 /$ S2212-5671(14)00463-8

[8] Molenaar, K. R, (2005) "Programmatic Cost Risk Analysis for Highway Megaprojects," Journal of Construction Engineering and Management, vol. 31, no. 3 pp. 343-353, 2005.https://doi.org/10.1061/(ASCE)0733-9364(2005)131: $3(343)$

[9] Anna A. Loyd, "A Comparison of Fuzzy Indices with Monte-Carlo Simulations for Risk Assessment at the Preliminary Stages of Transit Project Planning," Masters' Thesis, Technical University of Szczecin, Poland, 2006, pp. 1-107.

[10] Love, P. E. D., Sing, C., Carey, B., Kim, J. T, "Estimating Construction Contingency: Accommodating the Potential for Cost Overruns in Road Construction Projects, "Journal of Infrastructure Systems, vol. 21, no. 2, pp. 1-10, 2015. https://doi.org/10.1061/(ASCE)IS.1943-555X.0000221

[11] Heap Yih Chong, Robert Lopez, Jun Wang, Xiangyu Wang, Zeyu Zhao, "Comparative Analysis on the Adoption and Use of BIM in Road Infrastructure Projects," Journal of Management in Engineering, ASCE, vol. 32, no. 6, 2016. https://doi.org/10.1061/(ASCE)ME.1943-5479.0000460

[12] Araszkiewicz, K, "Building Information Modelling: An Innovative Way to Manage Risk in Construction Projects," International Journal of Contemporary Management, vol. 14, no. 3, pp. 23-40, 2015. DOI:10.4467/24498939IJCM.15.00 2.4304

[13] Likhitruangsilp, V., Malvar, M. J. S., Handayani, T. N, "Implementing BIM Uses for Managing Risk in Design-Build Projects," $16^{\text {th }}$ International Conference on Computing in Civil and Building Engineering, July, 2016, pp. 887-894. http://www.see.eng.osaka-u.ac.jp/seeit/icccbe 2016/

[14] Mahalingam A., Kashyap R., Mahajan C, "An Evaluation of The Applicability of 4D CAD on Construction Projects," Automation in Construction, Elsevier B. V, vol. 19, no. 2, pp. 148-159, 2010. https://doi.org/10.1016/j.autcon.2009.11.01 5 
[15] Dey, P. K, "Project Risk Management Using Multiple Criteria Decision-Making Technique and Decision Tree Analysis: A case study of Indian Oil Refinery," Production Planning and Control, vol. 23, no. 12, pp. 903-921, 2012. https://doi.org/10.1080/09537287.2011.586379

[16] Kwak, Y. H., Anbari, F. T, “Analyzing Project Management Research: Perspectives From Top Management Journals," International Journal of Project Management, Elsevier Ltd and IPMA, vol. 27, no. 5, pp. 435-446, 2009. https://doi.org/10.1016/j.ijproman.2008.08.004

[17] Shi, Q., Zhou, Y., Xiao, C., Chen, R., Zuo, J, “Delivery Risk Analysis Within The Context of Program Management Using Fuzzy Logic and DEA: A China Case Study," International Journal of Project Management, Elsevier Ltd and IPMA, vol. 32, no. 2, pp. 341-349, 2014. https://doi.org/10.1016/j.ijproman.2013.05.002

[18] Abd El Khalek, H, "Risk and Uncertainty Assessment Model in Construction Projects Using Fuzzy Logic," American Journal of Civil Engineering, vol. 4, no. 1, pp. 24-39, 2016. DOI: $10.11648 /$ j.ajce. 20160401.13

[19] Dang, C. N., Le-Hoai, L., Kim, S. Y., Nguyen, C. Van, Lee, Y. D., Lee, S. H, "Identification of Risk Patterns in Vietnamese Road and Bridge Construction: Contractor's Perspective," Built Environment Project and Asset Management, vol. 7, no. 1, pp. 59-72, 2017. https://doi.org/10.1108/BEPAM-11-2015-0065

[20] Niazi G. A., Painting, N, "Significant Factors Causing Cost Overruns in the Construction Industry in Afghanistan,"
Procedia Engineering, vol. 182, pp. 510-517, 2017. https://doi.org/10.1016/j.proeng.2017.03.145

[21] Rauzana A, "Identification and Assessment of Risk Factors Affecting Construction Projects in North Aceh, Indonesia," IOSR Journal of Business and Management, vol. 19, pp. 72-77, 2016. DOI: 10.9790/487X-1809047277

[22] Renault, B. Y., Agumba, J. N., Ansary, N, "An Appraisal of Critical Risk Factors in Construction Projects : Perspective of Contractors," Proceedings of the DII-2016 Conference on Infrastructure Development and Investment Strategies for Africa: Achieving Solutions for Renewable Energy and Sustainable Development, pp. 707-714.

[23] Iqbal, S., Choudhry, R. M., Holschemacher, K., Ali, A., Tamošaitienè, J, "Risk Management in Construction Projects." Technological and Economic Development of Economy, vol. 21, no. 1 pp. 65-78, 2015. https://doi.org/10.3846/20294913.2014.994582

[24] Tipili, L. G., Ilyasu, M. S, "Evaluating the impact of risk factors on construction projects cost in Nigeria." The International Journal of Engineering and Science, vol. 3, no. 6, pp. 10-15, 2014. http://www.theijes.com/papers/v3-i6/V ersion-3/B0363010015.pdf

[25] Chan, D. W. M., Chan, A. P. C., Lam, P. T. I., Yeung, J. F. Y., Chan, J. H. L, "Risk ranking and analysis in target cost contracts: Empirical evidence from the construction industry," International Journal of Project Management, Elsevier B.V., vol. 29, no. 6, pp. 751-763, 2011. https://doi.org/10.1016/j.ijproman.2010.08.003 